\title{
Estudo quantitativo e morfológico das regiões organizadoras de nucléolo coradas pela prata (AgNORs) em neoplasias benignas e malignas da glândula mamária da espécie canina
}

\author{
Alexander Proazzi VAZ- \\ CURADO ${ }^{1}$ \\ José Luiz GUERRA ${ }^{1}$ \\ Ricardo Augusto DIAS²
}

\section{Correspondência para:}

Alexander Proazzi Vaz-Curado, Embravet. Av. Conselheiro Alves, 194 CEP:11015-200 Santos-SPaproazzi@usp.br

Recebido para publicação: 02/02/2007 Aprovado para publicação: 31/01/2008

\begin{abstract}
1 - Departamento de Patologia da Faculdade de Medicina Veterinária e Zootecnia da Universidade de São Paulo, São Paulo-SP

2 - Departamento de Medicina Veterinária Preventiva e Saúde Animal da Faculdade de Medicina Veterinária e Zootecnia da Universidade de São Paulo, São Paulo-SP
\end{abstract}

\section{Resumo}

O alvo deste estudo foi apresentar um novo método de avaliação das regiões organizadoras de nucléolos (NORs), objetivando verificar a correlação entre malignidade das células tumorais com proliferação celular. Vinte e nove tumores foram analisados quanto aos aspectos morfológicos e quantitativos de regiões organizadoras de nucléolos coradas pela prata (AgNORs) e comparados à quatro glândulas mamárias normais utilizadas como controle. Os dados obtidos foram tratados pelos testes não-paramétrico de Kruskal-Wallis e "U" de Mann-Whitney. Os números médios de NORs dos grupos neoplásicos malignos incluindo carcinomas tubulares $(2,14 \pm 0,54)$, carcinomas papilíferos $(1,79 \pm 0,24)$ e carcinomas sólidos $(1,95 \pm$ $0,30)$ mostraram diferença significativa quando comparados ao grupo controle $(1,16 \pm 0,08)$. A análise morfológica das AgNORs mostrou que o padrão de apresentação da NORs do tipo I prevaleceu nos grupos neoplásicos benignos (75\% dos casos de adenoma tubular e $50 \%$ dos casos de carcinoma tubular), enquanto o tipo II prevaleceu nos grupos neoplásicos de comportamento maligno (54,5\% dos carcinomas papilíferos e 100\% dos carcinomas sólidos). O grupo controle mostrou na sua totalidade $(100 \%$ dos casos) predominância de NORs do tipo IV. O padrão do Tipo III não predominou em nenhum dos grupos envolvidos neste estudo. A análise da morfologia das AgNORs é uma ferramenta útil na determinação do prognóstica de alterações neoplásicas da glândula mamária canina.

\section{Introdução}

Os tumores derivados do tecido glandular mamário na espécie canina são de grande relevância na clínica veterinária, visto ocuparem a segunda posição em ocorrência entre as lesões tumorais desta espécie, compreendendo mais de $52 \%$ de todos os tumores caninos. ${ }^{1,2}$ Tradicionalmente, a determinação do grau de malignidade tem sido confiada ao grau de anaplasia das células, representado por: pleomorfismo nuclear, perda de polaridade, figuras atípicas de mitose e, invasividade das células tumorais em tecidos adjacentes. ${ }^{3}$ Estudos morfológicos de células cancerosas têm revelado variações na organização estrutural do núcleo celular. Contudo, até então, nenhuma dessas características pode ser considerada representativa como sinal de malignidade. Atenção particular tem sido dada à morfologia nucleolar, onde mudanças morfológicas na organização de proteínas ribonucleares nucleolar estão sendo repetidamente observadas em células neoplásicas. ${ }^{4,5,6,7}$ 
A capacidade de proliferação das células tumorais mostra-se um grande objeto de interesse na pesquisa com cânceres, especialmente quando considerada a relação entre atividade proliferativa e curso clínico. ${ }^{8}$ Regiões organizadoras de nucléolos (NORs) são segmentos de cromossomos na metáfase onde genes ribossomais estão localizados e que corresponde às constrições secundárias. ${ }^{9}$ Durante a interfase, as NORs estão localizadas nos centros fibrilares e estão intimamente associadas ao componente fibrilar denso do nucléolo. ${ }^{10,11,12}$ Estas estruturas contêm todos os componentes necessários para a síntese de rRNA e, portanto, a transcrição dos genes ribossomais. ${ }^{13}$ As NORs em interfase podem ser visualizadas à microscopia de luz, em amostras processadas rotineiramente utilizando métodos de coloração pela prata, devido a argirofilia que um grupo de proteínas associadas à ela apresenta. ${ }^{14}$ As NORs coradas pela prata são chamadas de AgNORs. ${ }^{15}$ Numerosos autores sugerem que o procedimento de coloração pela prata para observar as NORs de núcleos é adequado para avaliação prognóstica do curso das neoplasias. ${ }^{16}$

Uma grande variedade de métodos estão sendo introduzidos na avaliação da cinética celular na oncologia moderna, porém, poucos são aplicáveis em tecidos fixados em formol e embebidos em parafina. ${ }^{17}$ Uma série de trabalhos tem sido publicados relacionando marcadores de proliferação associados à antígenos nucleares, como MIB-1 e/ou PCNA, à AgNORs. Pich, Margaria e Chiusa ${ }^{18}$, estudando, em humanos, a atividade proliferativa em carcinomas mamários masculinos mostraram que a contagem de AgNORs é uma importante ferramenta prognóstica, pois, correlaciona-se fortemente com o tempo de sobrevida, o que foi corroborado pela demonstração da forte associação da positividade dos marcadores de proliferação imuno-histoquímicos PCNA e MIB-1 com a média de vida dos pacientes que sofriam desta afecção. Em animais, Castagnaro et al. ${ }^{19}$ conseguiram mostrar que a contagem média de AgNORs por célula é um índice de proliferação significativamente correlacionado com o tempo de sobrevida pós-operatório.

O objetivo deste trabalho é comparar a quantidade de NORs encontrada no núcleo das células componentes do tecido mamário normal de cadelas ovario-histerectomizadas, com o número de NORs presente nas células dos tumores benignos e malignos ocorridos nesta glândula, usando o método de coloração argirofílica (AgNOR), assim como, apresentar um novo método de avaliação das NORs relacionando sua morfologia e distribuição, objetivando verificar a correlação entre malignidade de células tumorais com proliferação celular.

\section{Material e Método}

O material utilizado neste trabalho consta de quatro casos de tecido mamário normal de cadelas ovario-histerectomizadas há pelo menos um ano e de 29 casos de tumores benignos e malignos da mesma glândula selecionados e classificados segundo a OMS, incluindo nove cães sem raça definida, seis cães de raça Poodle, quatro Pastores Alemães, dois Dobermann, dois Cocker Spaniel Inglês, dois Terrier Brasileiro e um de cada das seguintes raças: Dachshund, Akita, Boxer, Pinscher. As idades variavam de quatro a 15 anos (média: 9,13 anos). Para a classificação das lâminas foi utilizado o método de classificação histológica das neoplasias mamárias caninas propostas por Misdorp et $\mathrm{al}^{20}$. Infiltrado inflamatório ou macrofágico evidente, mais tumores com dois ou mais padrões histológicos de classificação diferentes foram utilizados como parâmetros de exclusão do trabalho.

\section{Histoquímica das NORs}

Dos casos selecionados, cortes de 5 $\mathrm{mm}$ de espessura em branco colocados em lâminas sem silano, foram submetidos à coloração argirofílica segundo a técnica adaptada do método proposto por Ploton et al. ${ }^{21}$. Os cortes estendidos em lâminas de vidro são submetidos a desparafinização e 
hidratação através de passagens sucessivas em xilol e álcool. As lâminas sofriam banho de 5 minutos em solução de álcool e ácido acético (3:1) e depois em água deionizada corrente por 5 minutos. Após receber solução de prata $50 \%$ misturada à solução de gelatina $1 \%$ na proporção de $2: 1$, as lâminas eram incubadas em câmara úmida por 30 minutos em estufa à $45^{\circ} \mathrm{C}$. Finalmente, as lâminas eram lavadas vigorosamente com água deionizada aquecida, desidratadas em soluções crescentes de álcool, clareadas em xilol e montadas com Permount sem nenhuma contracoloração.

Análise Quantitativa e Morfométrica As análises quantitativa e morfométrica das NORs de cada caso foram realizadas através da análise por imagem utilizando o "software" ImageLab versão 2.4, programa do Laboratório de Informática Dedicado à Odontologia (L.I.D.O.) da Faculdade de Odontologia da Universidade de São Paulo (F.O.U.S.P.).

Para análise morfométrica foram selecionadas imagens de 5 a 10 campos histológicos aleatoriamente, com o uso de objetiva de 100X em imersão, em microcópio de luz Leitz, modelo LaborluxS (Ernest Leitz Gmbtl, Deutschland), com finalidade de se estudar 200 núcleos.

As imagens, adquiridas por câmara de vídeo CCD acoplada ao microscópio, foram digitalizadas através de placa gráfica Íris-16 (extensão.I16) em um microcomputador IBM-PC-PS/1 (International Business Machines Corporation, USA). Através de um programa de captura (Microsoft ${ }^{(R)}$ VidCap - Video Capture Tool), o campo a ser analisado era colado para análise e processamento de imagem através de outro "software" ImagemLab. Depois de inserida e maximizada a imagem, acionava-se o ícone "contador manual" localizado na barra lateral de ferramentas. Com o cursor, cada NOR era localizada e simultaneamente o programa contava a quantidade "positiva" de pontos marcados na tela. A contagem dos núcleos foi feita com um contador manual de células Veeder-Root. Durante o procedimento de contagem, era feita a análise qualitativa das NORs, sendo avaliadas quanto às suas características morfológicas, conforme descrito posteriormente, e classificadas de acordo com o tipo mais freqüente. Após o término das análises morfométricas e quantitativas, todos os dados foram tabulados e transformados em arquivo texto, para posterior tratamento estatístico.

Tipo de Apresentação das NORs A análise do tipo de apresentação das NORs foi realizado segundo o método proposto por Sredni et al. ${ }^{22}$ no estudo de neoplasias do córtex adrenal em adultos e crianças, de acordo com a experiência desenvolvida durante a observação dos tumores e glândulas adjacentes, onde definiuse quatro padrões de apresentação das AgNORs baseados no número, forma e posição em relação à membrana nuclear, sendo cada caso classificado de acordo com o padrão predominante. O método de avaliação se deu como descrito anteriormente ocorrendo concomitantemente à análise morfométrica.

\section{Análise estatística}

Utilizaram-se testes de análise estatísticas não-paramétricas dadas as características dos dados obtidos, uma vez que os dados não apresentam uma distribuição normal por grupo. O teste utilizado foi o de Anderson-Darling. Para triagem da avaliação estatística dos grupos, o teste de detecção das diferenças entre os cinco grupos estudados (quatro grupos neoplásicos e o grupo controle) foi o de Kruskall-Wallis. Em seguida, como método para comparação dos grupos dois a dois, utilizamos o teste U de Mann-Whitney. Para proceder a análise estatística no programa de computador, os grupos controle, adenoma, carcinoma tubular, carcinoma papilífero e carcinoma sólido, receberam, respectivamente, a numeração 1, 2, 3, 4 e 5 . Do mesmo modo, os tipos I, II, III e IV de 
apresentação das NORs receberam, respectivamente, a numeração 1, 2, 3 e 4 .

\section{Resultados}

\section{Classificação histológica do tecido mamário normal e neoplásico}

Glândulas mamárias em repouso de cadelas ovario-histerectomizadas, que foram utilizadas como controle, revelaram, ao exame histológico, parênquima constituído de glândulas túbulo-alveolares compostas por uma monocamada de epitélio cúbico, cujos núcleos apresentaram-se ovalados, com cromatina densa, basofílicos, e com citoplasma acidofílico, cujos limites eram pouco definidos, envolvidos por uma camada de células mioepiteliais. Os adenomas tubulares caracterizavam-se por apresentar proliferação de células pequenas, hipercromáticas, cuboidais ou colunares que ocupavam, por vezes, o lúmen dos alvéolos e túbulos. O citoplasma exibia, ocasionalmente, vacuolizações. O lúmen de alguns alvéolos e túbulos, freqüentemente, eram dilatados e preenchidos por matriz proteinácea acidofílica. Os carcinomas tubulares apresentaram proliferações compostas por células hipercromáticas, muitas vezes pequenas, pouco diferenciadas, cujo crescimento exibiam um padrão tubular ou acinar. Os carcinomas papilíferos exibiram padrão de crescimento em forma de papilas irregulares com delicadas traves de tecido conjuntivo, as quais eram cobertas por estratificações irregulares de células com moderada a acentuada perda de polaridade. Em muitos casos, as estruturas cresciam dentro de cistos. Os carcinomas sólidos caracterizavam-se por proliferação de cordões sólidos de células anaplásicas, livres de qualquer estroma, dentro de túbulos ou ácinos que, não raro, invadiam o tecido conjuntivo adjacente.

\section{Análise Quantitativa e Morfométrica das NORs}

Em todos os tumores estudados as regiões organizadoras de nucléolo coradas pela prata foram visualizadas como pontos enegrecidos, por vezes acastanhados, localizados no interior dos núcleos. A tabela 1 mostra a análise quantitativa das NORs das células analisadas. Os dados representam o número total de casos analisados e o número total de células por caso, sendo que, de cada caso 200 células (ou próximo de 200 células) foram analisadas. $\mathrm{O}$ número mínimo e máximo de NORs, assim como as médias do número de NORs das células analisadas estão presentes na tabela 1 . Em relação ao número médio do total de NORs por células analisadas, através do teste de Kruskal-Wallis, observa-se diferença significativa comparando-se o grupo controle (Figura 1) $(243,75 \pm 21,79)$ com as células dos adenomas tubulares (Figura 2) $(377,75 \pm 133,42)$, com as células dos carcinomas tubulares (Figura 3) (421,50 \pm 116,99), dos carcinomas papilíferos $(378,00 \pm 51,71)$ e com as células dos carcinomas sólidos (Figura 4) (454,50 \pm 93,48) (Tabela 1). As análises pareadas feitas através do teste de Mann-Whitney mostraram diferença significativa quando comparados os grupos neoplásicos ao grupo controle $(\mathrm{p}<0,05)$. A tabela 2 mostra a freqüência do número médio de NORs por núcleo

Tabela 1 - Dados quantitativos das células e das regiões organizadoras nucleolares dos 29 tumores da glândula mamária canina

\begin{tabular}{cccccc}
\hline Tipo & $\mathrm{n}^{\circ}$ casos & \multicolumn{2}{c}{$\mathrm{n}^{\circ}$ células analisadas } & \multicolumn{2}{c}{$\mathrm{n} .^{\circ}$ total de NORs } \\
\hline & & Média $\pm \mathrm{DP}$ & (Variação) & Média \pm DP & (Variação) \\
CN & 4 & $209,75 \pm 8,66$ & $(200-218)$ & $243,75 \pm 21,79$ & $(228-276)$ \\
AT & 4 & $215,25 \pm 13,15$ & $(204-229)$ & $377,75 \pm 133,42$ & $(254-553)^{*}$ \\
CT & 6 & $200,83 \pm 10,85$ & $(182-213)$ & $421,50 \pm 116,99$ & $(305-553)^{*}$ \\
CP & 11 & $208,36 \pm 14,49$ & $(179-233)$ & $378,00 \pm 51,71$ & $(279-439)^{*}$ \\
CS & 8 & $232,25 \pm 34,23$ & $(192-296)$ & $454,50 \pm 93,48$ & $(293-601)^{*}$ \\
\hline
\end{tabular}

CN - Controle; AT - adenoma tubular; CT - carcinoma tubular; CP - carcinoma papilifero; CS - carcinoma sólido; *diferença estatisticamente significante (Mann-Whitney) $(p<0,05)$ 
Tabela 2 - Freqüência do número médio de NORs por núcleo das células componentes do grupo controle e dos tumores da glândula mamária canina

\begin{tabular}{lc}
\hline Classificação (n) & X NOR \\
\hline CN (4) & $1,16 \pm 0,08$ \\
AT (4) & $1,74 \pm 0,69$ \\
CT (6) & $2,14 \pm 0,54$ \\
CP (11) & $1,79 \pm 0,24$ \\
CS (8) & $1,95 \pm 0,32$ \\
\hline
\end{tabular}

CN - controle; AT - adenoma tubular; CT - carcinoma tubular; CP - carcinoma papilífero; CS carcinoma sólido

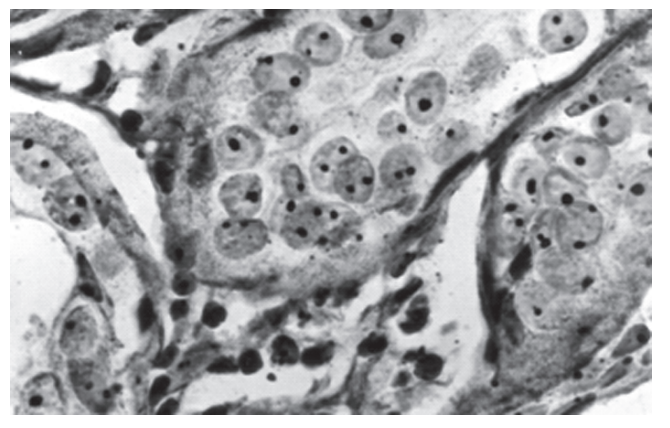

Figura 1 - Padrão de distribuição das AgNORs do Tipo IV - Tecido mamário de cão. Glândula Mamária Normal. Poucas (uma a quatro) AgNORs puntiformes (pequenas, redondas e uniformes) localizadas no centro ou na periferia do núcleo. Objetiva 100x

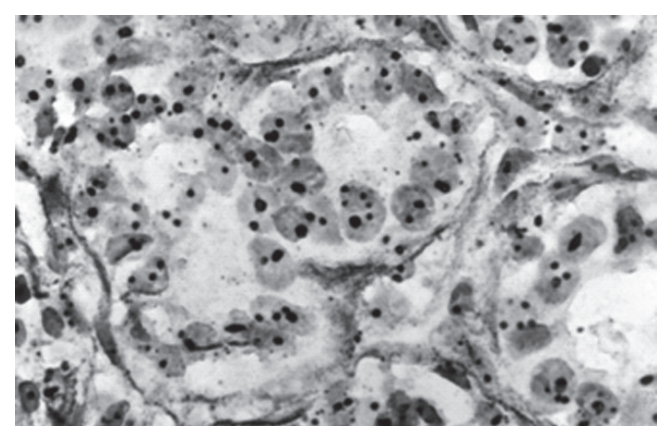

Figura 3 - Padrão de distribuição das AgNORs do Tipo II. Tecido mamário de cão. Carcinoma Tubular. Uma ou duas AgNORs grandes, redondas e uniformes, com tendência a localizar-se no centro do núcleo, acompanhadas por várias outras menores. Objetiva 100x

das células analisadas do grupo controle e dos tumores da glândula mamária. As análises pareadas feitas através do teste de Mann-Whitney mostraram que não houve diferença significativa em relação ao número de NOR por células do grupo controle $(1,16 \pm 0,08)$ comparado com adenoma tubular $(1,74 \pm 0,69),(p=0,14)$. Entre o grupo controle e os carcinomas tubulares $(2,14 \pm 0,54)$, os carcinomas

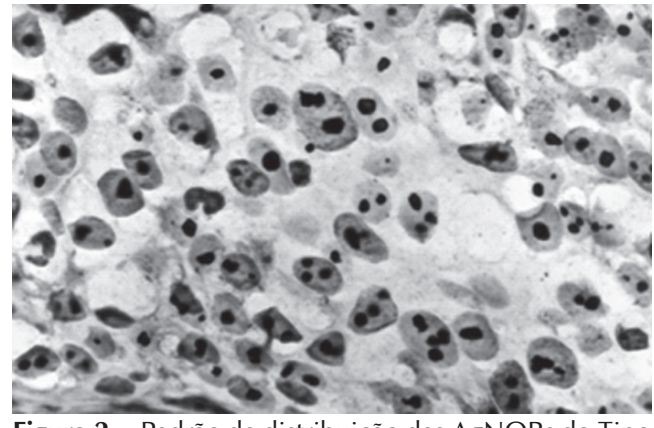

Figura 2 - Padrão de distribuição das AgNORs do Tipo I. Tecido mamário de cão. Adenoma Tubular. Poucas (uma a quatro) AgNORs de tamanho médio (correspondente ao nucléolo), redondas e uniformes localizadas no centro ou na periferia do núcleo. Objetiva $100 x$

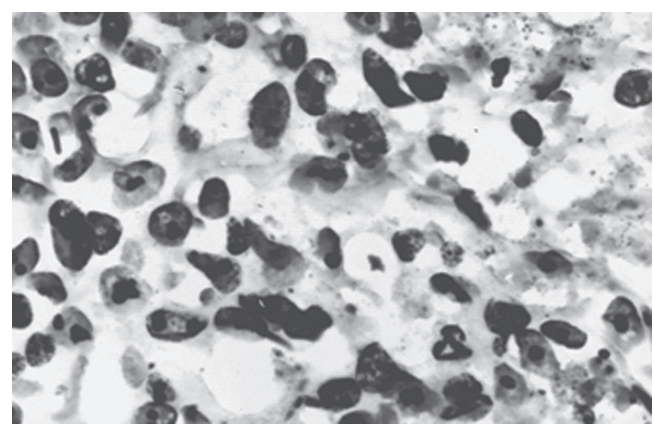

Figura 4 - Padrão de distribuição das AgNORs do Tipo III. Tecido mamário de cão. Carcinoma Sólido. AgNORs pleomórficas, de formas e tamanhos variados, distribuídas difusamente no núcleo. Objetiva 100x

papilíferos $(1,79 \pm 0,24)$ e os carcinomas sólidos $(1,95 \pm 0,30)$ houve diferença estatisticamente significativa $(\mathrm{p}=0,011, \mathrm{p}$ $=0,004, p=0,006$, respectivamente). Não houve, entretanto, diferença significativa entre os grupos neoplásicos quando comparados entre si. O teste de KruskalWallis mostrou diferença significativa entre os cinco grupos envolvidos neste estudo $(\mathrm{p}=0,016)$. 
Tipos de NORs nas Neoplasias Mamárias

A análise microscópica com objetiva de imersão revelou que os tumores benignos e malignos apresentaram predominância dos tipos morfológicos I e II (Figura 5.a e b, respectivamente) de NORs, segundo a classificação adotada. A distribuição percentual de apresentação das NORs está expressa na tabela 3. O padrão de apresentação de NORs do tipo III (Figura 5.c) não predominou nenhum dos grupos histológicos envolvidos neste estudo. Em relação à freqüência dos tipos
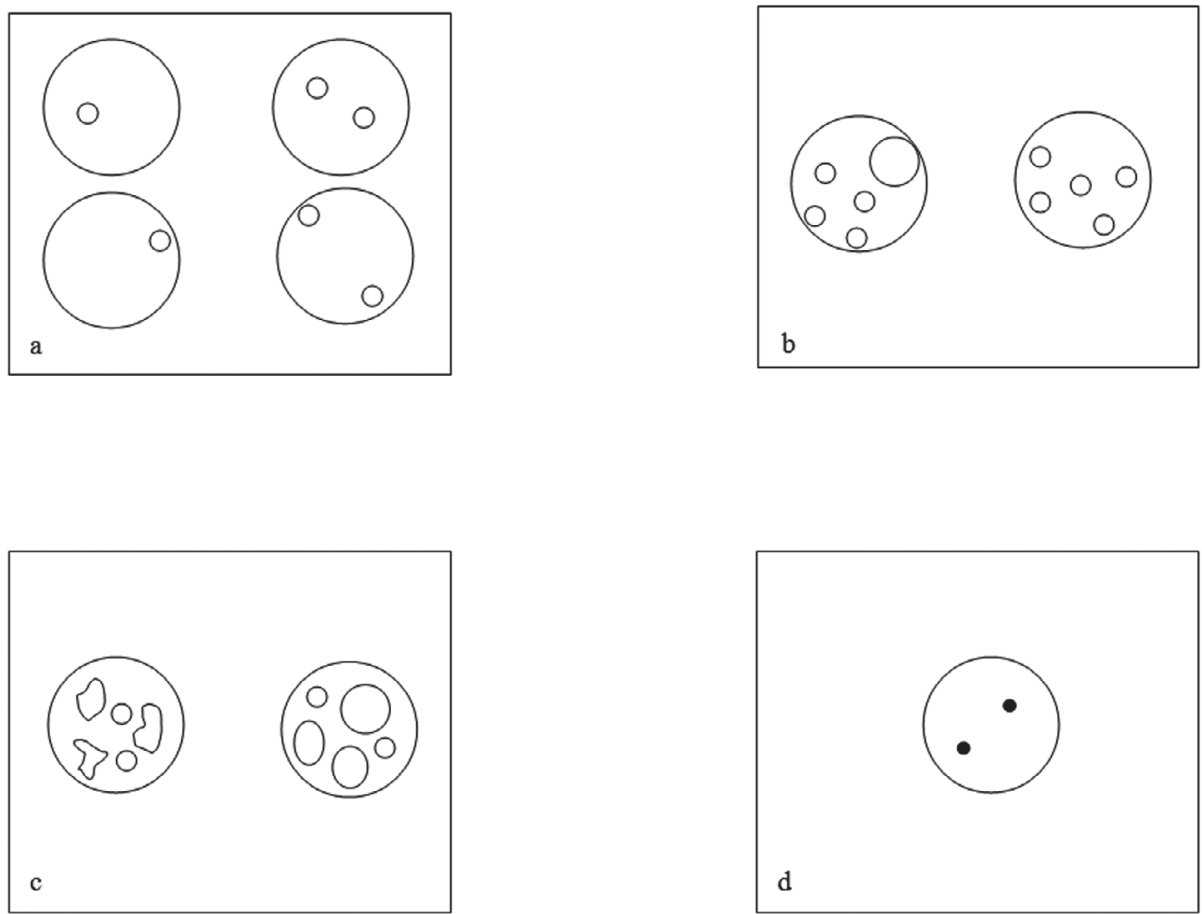

Figura 5 - Tipo de apresentação das NORs segundo o método proposto por SREDNI (2003). a) Tipo I: Poucas (uma a quatro) AgNORs de tamanho médio (correspondente ao nucléolo), redondas e uniformes localizadas no centro ou na periferia do núcleo; b) Tipo II: Uma ou duas AgNORs grandes, redondas e uniformes, com tendência a localizar-se no centro do núcleo, acompanhadas por várias outras menores; c) Tipo III: AgNORs pleomórficas, de formas e tamanhos variados, distribuídas difusamente no núcleo; d) Tipo IV: Poucas (uma a quatro) AgNORs puntiformes (pequenas, redondas e uniformes) localizadas no centro ou na periferia do núcleo

Tabela 3 - Freqüência dos tipos morfológicos de apresentação de NORs nas células componentes do grupo controle e dos tumores da glândula mamária canina

\begin{tabular}{l|cccc}
\hline \multirow{2}{*}{ Classificação(n) } & \multicolumn{4}{|c}{ Padrão Morfológico } \\
\cline { 2 - 4 } & I & II & II & IV \\
\hline Controle (4) & - & - & - & $100 \%$ \\
AT (4) & $75 \%$ & $25 \%$ & - & - \\
CT (6) & $50 \%$ & $50 \%$ & - & - \\
CP (11) & $45,45 \%$ & $54,54 \%$ & - & - \\
CS (8) & - & $100 \%$ & - \\
\hline CN - Controle; AT - adenoma tubular; CT - carcinoma tubular; CP - carcinoma papilífero; CS - \\
carcinoma sólido
\end{tabular}


morfológicos de apresentação de NORs nas células analisadas, as células do grupo controle, quando comparadas ao grupos tumorais, através do teste de duas proporções, mostraram diferença significativa $(\mathrm{p}<0,05)$. O grupo controle mostrou na sua totalidade (100\% dos casos) predominância de NORs do tipo IV (Figura 5.d) (padrão predominante somente neste grupo). Setenta e cinco por cento dos casos de adenoma tubular apresentaram padrão morfológico de apresentação das NORs do tipo I e $25 \%$ dos casos do tipo II. Os carcinomas tubulares mostraram freqüência similar para os tipos I e II (50\% para cada padrão). Dos casos de carcinoma papilífero, $45,45 \%$ apresentaram padrão de apresentação do tipo I, e 54,54\% apresentaram o tipo II. Finalmente, em todos os espécimes analisados de carcinoma sólido, o padrão predominante foi do tipo II. Pelo teste de Mann-Whitney não houve diferença significativa dos padrões de apresentação das NORs quando pareados adenomas tubulares, carcinomas tubulares, e carcinomas papilíferos $(\mathrm{p}>0,05)$. Houve diferença significativa entre os grupos adenoma tubular e carcinoma sólido $(p=0,007)$.

\section{Discussão}

A proposta deste trabalho foi estudar se a avaliação da atividade celular poderia representar uma ferramenta prognóstica nos tumores de glândula mamária canina, através de um marcador de proliferação celular argirofílico (AgNOR), pragmático, de custo baixo, rápida confecção, passível de ser aplicado na rotina de laboratórios. Sabe-se que há muitos métodos com valor prognóstico tendo como alvo a proliferação celular que podem ser aplicados em tecidos fixados e incluídos em parafina e que estão sendo introduzidos à patologia cirúrgica, permitindo inclusive a realização de estudos retrospectivos. Atenção particular tem sido dada à morfologia nucleolar, onde mudanças morfológicas na organização de proteínas ribonucleares estão sendo repetidamente observadas em células neoplásicas. ${ }^{4,5,6,7}$ A expressão aumentada de AgNORs tem sido detectada em células cancerosas quando comparadas à células normais ou benignas em alguns órgãos. Isto tem sugerido que AgNORs refletem o potencial maligno. ${ }^{3,23,24,25,26}$ Ristimäki et al. ${ }^{8}$ e Parrett et al ${ }^{27}$, demonstraram em estudo com carcinoma de cólon e mama, respectivamente, que estes tumores expressam altos níveis de proteína cicloxigenase-2, quando comparados ao tecido normal adjacente. Muitos autores vêem relacionando processos neoplásicos com agentes inflamatórios, e concluem pesquisas acerca deste assunto. $O$ fato de que substâncias liberadas por células componentes de processo inflamatório ativo atuam diretamente sobre o tecido neoplásico adjacente, incentivou-nos a exclusão de espécimes "contaminados", a fim de se reduzir a ação de agentes externos sobre o comportamento celular. O processo de seleção também ocorreu para o grupo controle, do qual fizeram parte somente fêmeas ovário-histerectomizadas há pelo menos um ano, para que não houvesse interferência de agentes hormonais ativos. Crocker ${ }^{28}$ encontraram que o número total de AgNOR em lesões malignas de mama excedem significativamente aqueles encontrados no tecido mamário normal ou mesmo em lesões benignas de mama. Fato corroborado em nosso estudo, já que houve diferenças significativas em relação ao número médio do total de NORs por células analisadas comparando-se o grupo controle com carcinoma tubular, carcinoma papilífero e carcinoma sólido. Porém, quando comparado adenoma tubular com grupos neoplásicos malignos, não houve diferenças significativas. Os tecidos neoplásicos estudados neste trabalho apresentaram, em relação ao número médio de NORs por núcleo, diferença significativa entre o grupo controle e os grupos neoplásicos de carcinoma tubular, carcinoma papilífero e carcinoma sólido. Já quando comparados os grupos controle e adenoma tubular, e quando pareadas lesões malignas entre si, não 
houve diferença significativa.

$\mathrm{Na}$ literatura atual, outros trabalhos envolvendo o estudo das NORs tentam incrementar a informação prognóstica acrescentado a avaliação de diferentes marcadores de proliferação ao estadiamento histológico. Assim, não só o número, mas também a área que as NORs ocupam no núcleo, tem um importante papel como fator prognóstico no tempo livre de doença. ${ }^{15,29}$ Porém, existe uma notável dificuldade, entre os trabalhos analisados, de se determinar uma adequada linha de corte no que tange à análise morfométrica, tornando, ainda, impossível determinar o real comportamento biológico do câncer.

No sentido de se aprimorar o estudo das AgNORs, Kida, Takano e Okudaira ${ }^{30}$ observaram diferença nos padrões de apresentação das AgNORs em 10 adenomas e cinco carcinomas adrenocorticais, e concluíram que a observação cuidadosa das AgNORs pode facilitar a distinção entre tumores adrenocorticais benignos e malignos. Durante a observação cuidadosa e repetida dos tumores adrenocorticais de adultos e crianças para quantificação das NORs, Sredni et al. ${ }^{22}$ definiram quatro padrões básicos de apresentação de AgNORs, classificando cada tumor com o padrão predominante. A metodologia utilizada foi extrapolada para esse estudo. Em nossa avaliação observamos que o tipo IV limitou-se às glândulas mamárias em repouso, utilizadas aqui como controle. Este achado corrobora com Sredni el al. ${ }^{22}$ que observaram predominância do tipo IV nas glândulas adrenais contralaterais normais (tecido controle) às glândulas adrenais neoplasias. O padrão tipo III, o qual foi observado somente nos tumores adrenocorticais pediátricos, não prevaleceu em nenhum espécime envolvido neste trabalho. Vale lembrar que as células das glândulas adrenais e mamária, inicialmente, são provenientes de camadas embriológicas distintas. A composição e organização de suas estruturas, assim como, o produto de suas atividades sintéticas também difere. Portanto, não se pode descartar a hipótese de que o modo de apresentação das alterações proveniente de mutações carcinogênicas seja diferente entre estes tecidos no que tange à análise das AgNORs. O padrão morfológico do tipo I e II predominaram nos grupos neoplásicos deste estudo. O padrão de apresentação de NOR do tipo I predominou em adenomas tubulares $(75 \%)$. Em carcinomas tubulares, a incidência dos padrões de apresentação das NORs do tipo I e II apareceu em igual proporção $(50 \%)$. Os carcinomas papilíferos exibiram ligeira predominância do padrão de apresentação do tipo II $(54,54 \%)$. Os carcinomas sólidos apresentaram exclusivamente o padrão do tipo II (100\%). Estes achados vão ao encontro daqueles encontrados por Sredni et al. ${ }^{22}$, pois, os tumores adrenais de adultos apresentaram predominância do tipo histológico I (56\%) e II (aproximadamente 30\%). Em humanos, observa-se influência dos padrões de AgNOR sobre a sobrevida livre de doença, sendo o tipo I característico dos tumores clinicamente benignos, e o tipo II característico dos tumores clinicamente malignos. Segundo Bostock ${ }^{1}$, dentro do grupo de carcinomas simples, uma ordem de aumento de malignidade foi encontrada: carcinomas não-infiltrativos, carcinomas tubulo-papilares, carcinomas sólidos e carcinomas anaplásicos. Como observado em nosso trabalho, houve diferença significativa entre os grupos adenoma tubular, com predominância do padrão morfológico do tipo I, e carcinoma sólido onde predominou o tipo II. Com estes dados podemos considerar que os tumores de glândula mamária com o padrão morfológico do tipo I podem ser relacionados com prognóstico favorável, enquanto que o padrão morfológico do tipo II, aqui observado nas neoplasias de caráter mais agressivo, pode se correlacionar com prognóstico desfavorável. Estas considerações nos dão margem a concluir que mais estudos devam ser feitos em relação ao padrão de apresentação das AgNORs, e que neoplasias de outros tecidos sejam avaliadas de modo a aperfeiçoar a 
metodologia aqui aplicada, visto que a análise da morfologia das AgNORs têm-se mostrado uma promissora ferramenta prognóstica de alterações neoplásicas.

\section{Conclusão}

A análise da morfologia das AgNORs é uma ferramenta útil na determinação do prognóstica de alterações neoplásicas da glândula mamária canina.

\section{Agradecimentos}

Ao Doutores Moacyr D. Novelli e Ricardo Alves de Mesquita do Departamento de Patologia Geral da Faculdade de Odontologia da USP e à Dra. Simone Treiger Sredni do Departamento de Patologia do Hospital do Câncer.

\title{
Quantitative and morphological study of silver staining nucleolar organizer regions (AgNORs) in benign and malignant neoplasms of the canine mammary gland
}

\begin{abstract}
s
The aim of this study was try to present a new method of evaluation of the nucleolar organizer regions (NORs) being related its morphology and distribution, objectifying to verify the correlation between malignancy of tumoral cells with cellular proliferation. Twenty-nine tumors were analyzed with regard to quantitative and morphological aspects of the silver staining nucleolar organizer regions (AgNORs) and compared to four normal mammary glands used as control. The data obtained were submitted to non-parametric KruskalWallis and Mann-Whitney " $U$ " tests. The mean NORs counts of the malignant neoplastic groups tubular carcinomas (2.14 \pm 0.54$)$, papillary carcinomas $(1.79 \pm 0.24)$ and solid carcinomas $(1.95 \pm 0.30)$ showed significant difference when compared with the control group $(1.16 \pm$ 0.08). Morphological analysis of AgNORs revealed that the expression pattern of type I NORs predominate in the benign histological groups ( $75 \%$ of the tubular adenoma cases and $50 \%$ of the tubular carcinoma cases), whereas type II NORs pattern prevailed in the malignant behavior neoplastic groups $(54,5 \%$ of the papillary carcinoma and $100 \%$ of the solid carcinoma cases). Control group showed total predominance $(100 \%$ of the cases) of type IV NORs. Expression pattern of the type III NORs did not prevail in neither histological group encompassed by this study. Evaluation of AgNORs morphology reveals an useful tool for prognosis assessment of neoplastic alterations of the canine mammary gland.
\end{abstract}

\section{Referências}

1 BOSTOCK, D. E. Neoplasia of the skin and mammary glands in dogs and cats. In: BOSTOCK, D. E. Current veterinary therapy. Philadelphia: Kirk RW, 1977. p. 493-496.

2 BOSTOCK, D. E. Veterinary professional development series: Canine and feline mammary neoplasms. Br. Vet. J., v. 142 , p. 506-515, 1986.

3 CROCKER, J. Nucleolar organiser regions. Curr. Top.
Key-words: AgNORs.

Mammary neoplasms. Prognostic. Morphological analysis. Dogs. 
7 WISCHNITZER, S. The submicroscopic morphology of the interphase nucleus. Int. Rev. Cytol., v. 34, p. 1 48, 1973.

8 RISTIMÄKI, A. et al. Expression of cyclooxygenase-2 in human gastric carcinoma. Cancer Res. v. 57, p. 127680, 1997.

9 HOWELL, W. M. Selective staining of nucleolus organizer regions (NORs). In: $\mathrm{BUSCH} \mathrm{H}$.; ROTHBLUM, L. The cell nucleus. New York: Academic Press, 1982. p. 89-143.

10 BOURGEOIS, C. A. et al. Silver stainig of NORs in electron microscopy. Exp. Cell Res., v. 123, p. 449452, 1979.

11 HERNANDEZ-VERDUN, D. et al. Ultrastructural localization of AgNOR stained proteins in the nucleolus during the cell cycle and in other nucleolar structures. Chromosoma, v. 79, p. 349-362, 1980.

12 HERNANDEZ-VERDUN, D. Structural organization of the nucleolus in mammalian cells. Methods Achiev. Exp. Pathol., v. 12, p. 26-62, 1986.

13 DERENZINI, M.; THIRY, M.; GOESSENS, G. Ultrastructural cytochemistry of the mammalian cell nucleolus. J. Histochem. Cytochem., v. 38, p. 1237 1256, 1990.

14 THERÉ, D. et al. Nucleolar size and activity are related to $\mathrm{pRb}$ and $\mathrm{p} 53$ status in human breast cancer. J. Histochem. Cytochem., v. 52, n. 12, p. 1601-1607, 2004.

15 DERENZINI, M. et al. The prognostic value of the AgNOR parameter in human breast cancer depends on the pRb and p53 status. J. Clin. Pathol., v. 57, p. 755761, 2004.

16 VAJDOVICH, P. et al. Use of the argyrophilic nucleolar region method for cytologic and histologic examination of the lymph nodes in dogs. Vet. Pathol., v. 41 , p. $338-345,2004$.

17 CROCKER, J. Molecular and immunohistological aspects of cell proliferation. In: CROCKER, J. Molecular biology in histopathology. New York: J Wiley, 1994. p. 93-120.

18 PICH, A.; MARGARIA, E.; CHIUSA, L.; Proliferative activity is a significant prognostic factor in male breast carcinoma. Am. J. Pathol., v. 145, v. 2, p. 481-489, 1994.

19 CASTAGNARO, M.; CASANOLEC C.; RU, G.
Argyrophilic nucleolar organiser regions (AgNORs) count as indicator of post-surgical prognosis in felin mammary carcinomas. Res. Vet. Sci., v. 64, p.97-100, 1998.

20 MISDORP, W. et al. Histological classification of the mammary tumours of the dog and the cat. Washington, D.C: Armed Forces Institute of Pathology, 1999. 59 p. (WHO international histological classification of tumours of domestic animals; $2^{\text {nd }}$ series, v. 7).

21 PLOTON, D. et al. Improvement in the staining and the visualization of the argyrophilic proteins of the nucleolar organizer region at the optical level. Histochem. J., v. 18, p. 5-14, 1986.

22 SREDNI, S. T. et al. Adrenocortical tumours in children and adults: a study of pathological and proliferation features. Pathology, v. 35, p. 130-135, 2003.

23 DERENZINI, M.; PESSION, A; THERÉ, D. Quantity of nucleolar silver-stained proteins is related to proliferating activity in cancer cells. Lab. Invest., v. 63, p. 137-140, 1990.

24 OFNER, D. et al. Silver stained nucleolar organizer regions proteins (AgNORs) as a predictor of prognosis in colonic cancer. J. Pathol., v. 162, p. 43-49, 1990.

25 SCHMITD, K. W. Silver stained nucleolar organizer regions proteins (AgNORs) as a predictor of prognosis in colonic cancer. J. Pathol., v. 162, p. 43-49, 1990.

26 YANG, P.; HUANG, G. S.; ZHU, X. S. Role of nucleolar organizer regions in the differentiating malignant from benign tumours of the colon. J. Clin. Pathol., v. 43, p. 235-238, 1990.

27 PARRETT, M. L. et al. Cyclooxygenase-2 gene expression in human breast cancer. Int. J. Oncol., v. 10, p. 503-507. 1997.

28 CROCKER, J. Evaluation of nucleolar organiser region-associated proteins in breast malignancy. R. Smith \& J. Crocker. Histopathology, v. 12, p. 113-125, 1998.

29 GIUSEPPE, S. et al. Prognostic value of histologic stage and proliferative activity in canine malignant mammary tomours. J. Vet. Diagn. Invest., v. 14, p. 2534, 2002.

30 KIDA, Y.; TAKANO, Y.; OKUDAIRA, M.; Argirophilic nucleolar organiser regions in human adrenocortical neoplasms. J. Cancer Res. Clin. Oncol. v. 119, p. 49-54, 1992. 